\title{
Correlation of CCV Between In-Cylinder Swirl Ratio and Polar Velocity Profile in Valve Seat Region Using LES Under Motored Engine Condition ${ }^{\star}$ Xiaofeng Yang", and Tang-Wei Kuo
}

\author{
GM Global R\&D, 800 N Glenwood Ave., Ml 48340-2925, Pontiac - USA \\ e-mail: xiaofeng.yang@gm.com \\ *Corresponding author
}

\begin{abstract}
An analysis of Transparent Combustion Chamber (TCC3) engine Large-Eddy Simulation (LES) result was carried out to investigate Cycle-to-Cycle Variation (CCV) correlation between incylinder swirl ratio and flow in the valve seat region of the intake port to address a challenging question on "What causes CCV of in-cylinder flow". Polar Velocity (PV) profile, mean velocities normal to a ringshaped cutting surface in the valve seat region, is calculated to depict intake port flow. A Net Polar Velocity (NPV) can be defined by performing the vector sum of the polar velocity around the intake valve. A standard deviation of $P V$ is also calculated from azimuthal distribution of $P V$ magnitudes relative to its mean value. The analysis of 18 LES cycles of TCC3 engine with a two-valve, pancake-shaped combustion chamber shows that similar CCV of in-cylinder swirl ratio patterns are observed at different crank angles from Intake Valve Opening (IVO) to Exhaust Valve Opening (EVO). Further analysis shows clear correlations of CCV between in-cylinder swirl ratio and NPV magnitude and the standard deviation of PVat selected crank angles from IVO to EVO. The correlations get significantly better with the ring-shaped cutting surface moves from up-stream to downstream of the valve-seat region. This study reveals that the CCV of in-cylinder swirl ratio is built up gradually from upstream to downstream in the intake port and valve-seat region. Further evaluation of the analysis method is planned for a four-valve engine as an evaluation metric for better engine intake port design and combustion chamber optimization.
\end{abstract}

\section{INTRODUCTION}

New automotive engine technologies promise to achieve improved fuel economy with reduced emissions. However, these technologies are more sensitive to stochastic processes and can suffer from increased cyclic variability. Large-Eddy Simulation (LES) is an important computational tool for understanding the critical processes that impact cyclic variability, and eventually can be used to mitigate their occurrence.

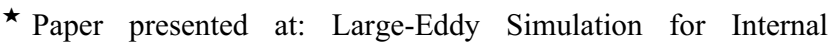
Combustion Engines, Rueil-Malmaison, France, 30 November 1 December 2016.
}

The computational tool of LES has been increasingly researched and developed for the last two decades [1] for better in-cylinder flow predictions. LES captures Cycle-toCycle Variations (CCV) as opposed to cycle-averaged mean computations of RANS, and is therefore more accurate. A recent effort of GM's R\&D and other organizations has been to understand and describe the nature of stochastic flows in internal combustion engines through concerted Particle Image Velocimetry (PIV) measurements and LES [2-9].

There are various intrinsic flow features inside an IC engine cylinder like swirl, tumble, intake jet, compression flow from piston, etc. which can be sources of the CCV of incylinder flows. Present paper develops an analysis procedure to evaluate the effects of intake port flow on CCV of the swirl ratio, based on LES results of motored Transparent 


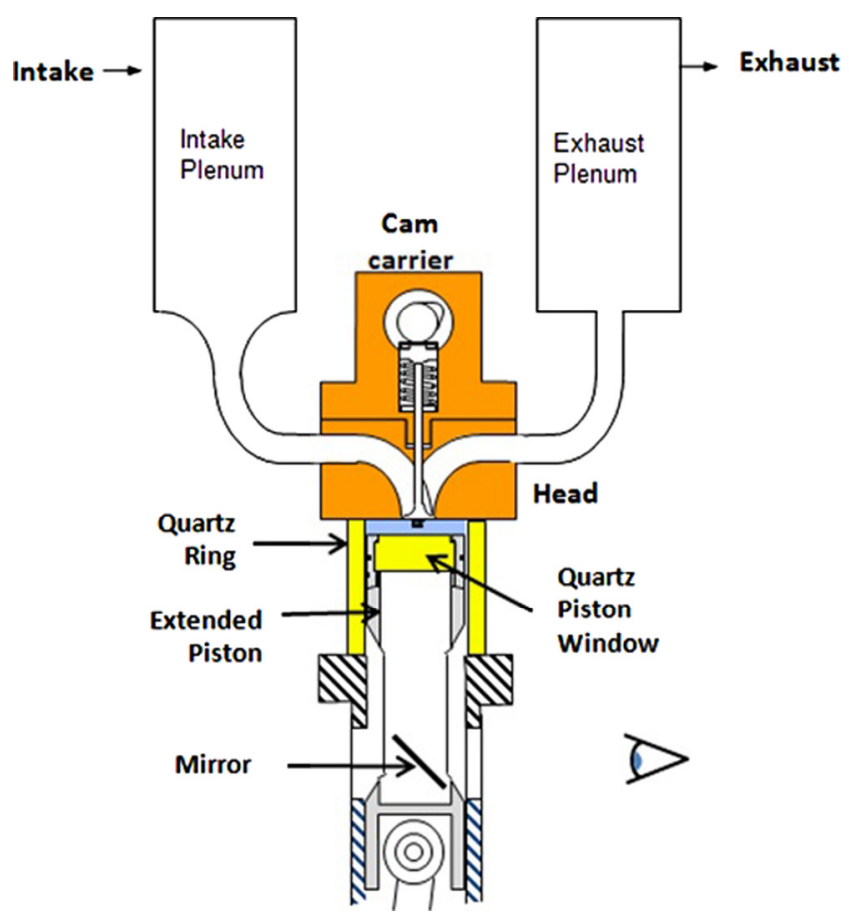

Figure 1

Schematics of Transparent Combustion Chamber (TCC3) engine.

Combustion Chamber (TCC3) engine. The overall goal is to develop physics-based computational tools for a more effective design of internal combustion engines of the future.

In an attempt to work towards providing elements for answering the question of what causes CCV of in-cylinder flows, the following questions were explored:

- Is there any correlation of CCV between in-cylinder swirl ratios at different crank angles during the four-stroke cycle?

- Is there any correlation of CCV between in-cylinder swirl ratio and intake port flow?

\section{TCC3 ENGINE}

An optical engine test setup was developed for the specific purpose of supporting the development and validation of a range of LES approaches [2,3]. The test setup features a single cylinder optical engine connected to intake and exhaust plenums via intake and exhaust runners, respectively. Figure 1 shows the engine features: a two-valve head and simple intake and exhaust port geometries with a pancake-shape combustion chamber coupled with a full quartz liner for maximum optical access. The engine has a bore of $92 \mathrm{~mm}$, a stroke of $86 \mathrm{~mm}$ and intake and exhaust valve diameter of $30 \mathrm{~mm}$. The geometric compression ratio is 10.0. Previous work [9] gives details of the other parameters like intake and exhaust valve lift profiles, engine specifications and intake and exhaust geometries.

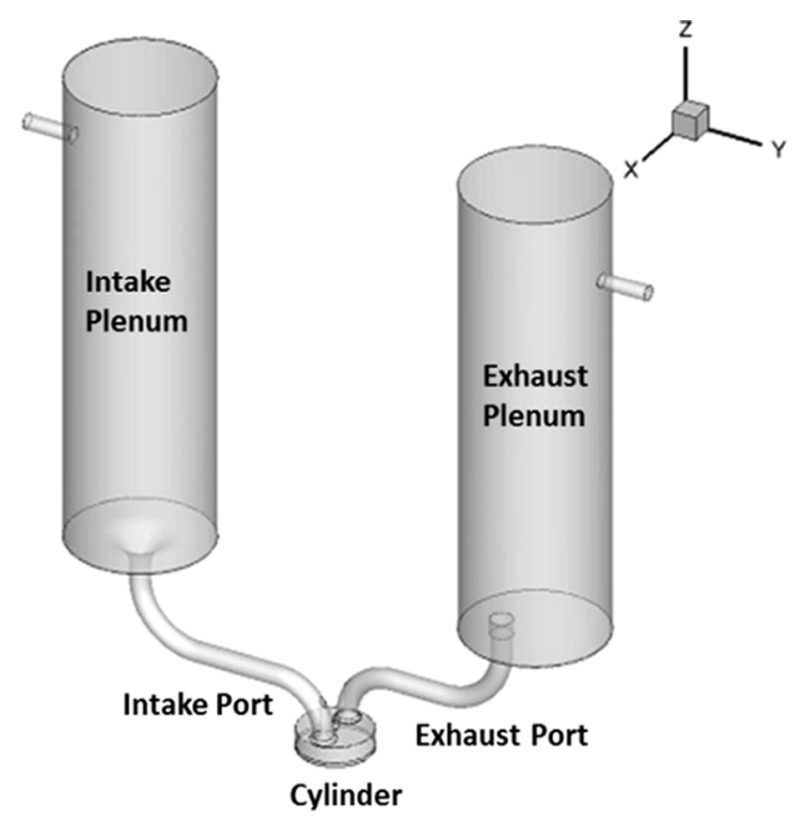

Figure 2

CFD model of TCC3 engine.

\section{CFD SETUP AND VALIDATION}

A commercial CFD code CONVERGE v2.1 [10] is used for this LES study of engine in-cylinder flows. CONVERGE uses a modified cut-cell Cartesian method that eliminates the need for the computational grid to be morphed with the geometry of interest while still properly representing the geometry [11]. At runtime, CONVERGE uses the supplied triangulated surface to cut the cells into a smaller irregular cells (i.e. cut-cell) that are intersected by the surface. Any cell can be cut by an arbitrary number of surface triangles, thus allowing the grid to represent the boundary accurately. All computed values are collocated at the center of the computational cell. To prevent checker boarding, the Rhie and Chow [12] algorithm is employed. All of the conservation equations are solved using the finite volume method. In finite volume mode, spatial derivatives are calculated by blending 2 nd order scheme. CONVERGE utilizes an implicit time integration scheme, and during the exhaust stroke the maximum CFL number was doubled (from 1 to 2 ) to reduce computation time. The transport equations are solved using the Pressure Implicit with Splitting of Operators (PISO) method of Issa [13]. The oneequation eddy viscosity dynamic structure turbulence model [14] is used for the LES with the Werner and Wengle wall model [15] to handle the flow and thermal boundary layers. CONVERGE can be run in parallel on shared memory machines. The parallelization is done using Message Passing Interface (MPI) so that both shared and distributed machines can be used for parallel runs. The wave dynamics of complete engine experimental setup is simulated with GT-Power, a detailed 1-D flow model. The 1-D model is validated with 


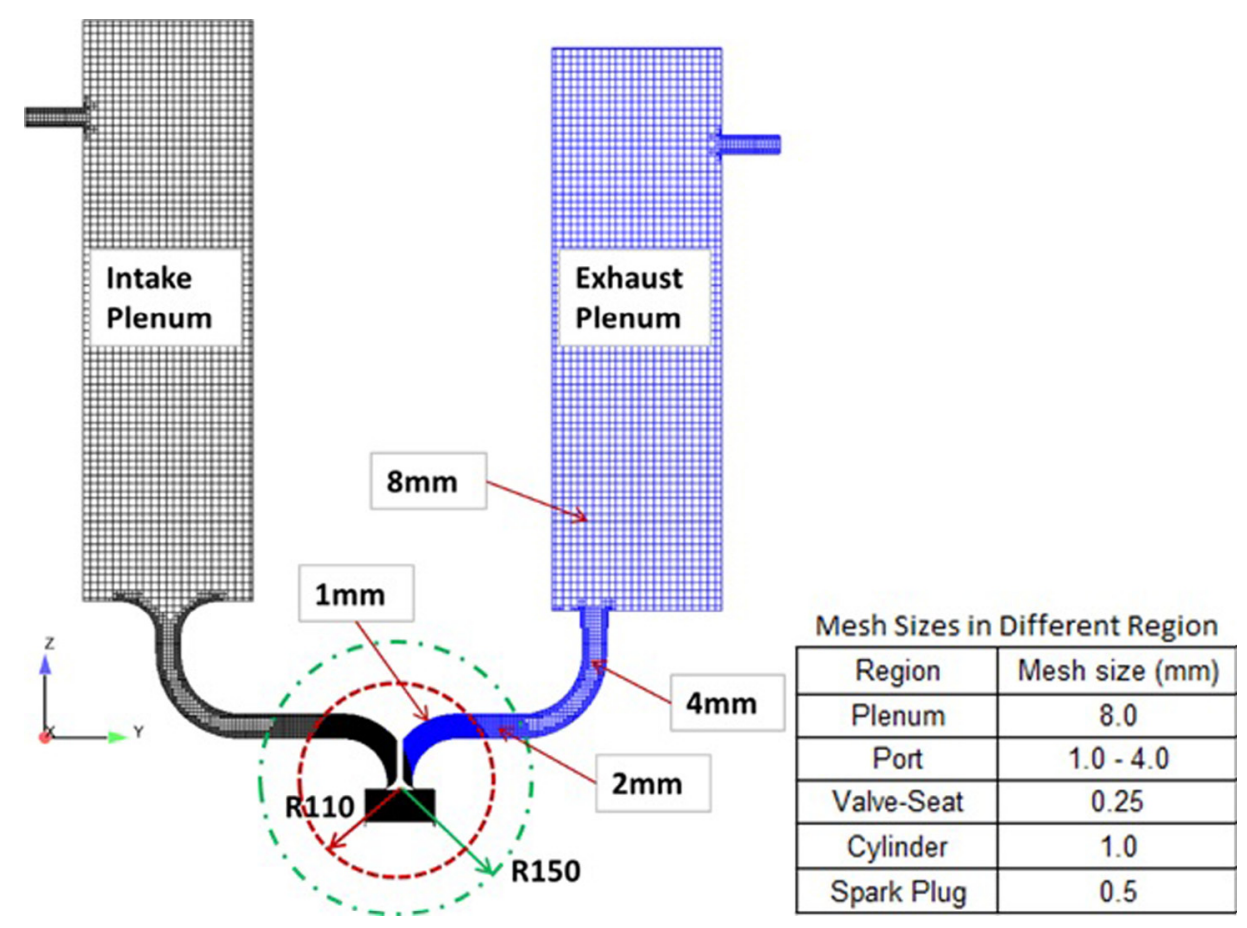

Figure 3

Meshing arrangement.

experimental measurements and used to provide the initial and boundary conditions for LES [3]. Figure 2 shows the CFD model of TCC3 optical Engine.The meshing arrangement is shown in Figure 3 and mesh sizes in different region are listed in the table. The mesh sizes are $2 \mathrm{~mm}$ and $1 \mathrm{~mm}$ in the regions covered by two embedded spheres with radius of $150 \mathrm{~mm}$ and $110 \mathrm{~mm}$, respectively [3].

The LES calculations were performed for motored engine condition at engine speed of $1300 \mathrm{RPM}$ and intake plenum pressure $40 \mathrm{kPa}$. The LES results were validated by the PIV measurements in the previous studies $[2,3,8,9]$. The flow fields over $Z=-30 \mathrm{~mm}$ plane (the origin located on center of the flat cylinder head) are compared between PIV measurements and LES ensemble-averaged results at four crank angles: 420, 460, 540 and 660 Crank Angle Degrees (CAD) in Figure 4. The two circles indicate the outlines of the cylinder bore and the PIVoptical access window, respectively. The LES simulations give quantitative predictions of flow field at the plane of $Z=-30 \mathrm{~mm}$. In this study, the LES results of first 22 cycles are selected and first 4 cycles are discarded to eliminate the initial condition effect.

\section{CHARACTERIZATION OF FLOW THROUGH THE INTAKE VALVE}

\subsection{Intake Port Polar Radial Velocity Profile}

A schematic ring-shaped cutting surface, shown in Figure 5, is discretized into 360 sections with $1^{\circ}$ increment in the circumferential direction and $0.5 \mathrm{~mm}$ spacing $(20$ cells for valve lift of $10 \mathrm{~mm}$ ) in the longitudinal direction. The flow velocities predicted by LES are mapped onto the meshes on the ring-shaped cutting surface and the normal velocity component (normal to the cutting surface) is calculated at each mesh point. Intake port Polar Velocity (PV) is then calculated by averaging the normal velocity component over all sections. The resulting PV profile as a function of circumferential angle $\alpha$ around the valve axis is shown in Figure 6 (thick solid red line). The thick solid black line represents the intake valve diameter and serves as the starting points of the polar velocity scale $(0 \mathrm{~m} / \mathrm{s})$. The thin dot-dashed black line is the polar velocity scale for $100 \mathrm{~m} / \mathrm{s}$. The thick dashed black lines indicate the intake port orientation and the thin solid black line shows the position of the liner.

\subsection{Net Polar Velocity}

A Net Polar Velocity (NPV) is defined by performing the vector sum of intake port Polar Velocity (PV) around the intake valve axis from $\alpha=0^{\circ}$ to $\alpha=360^{\circ}$ to represent the net intake flow magnitude and direction, as indicated by a red arrow in Figure 6. The $X$ and $Y$ components of the NPV are defined as:

$$
\begin{aligned}
& U_{N P V}=\frac{\sum_{\alpha=0}^{\alpha=360} u_{\alpha}}{360}, \\
& V_{N P V}=\frac{\sum_{\alpha=0}^{\alpha=360} v_{\alpha}}{360},
\end{aligned}
$$




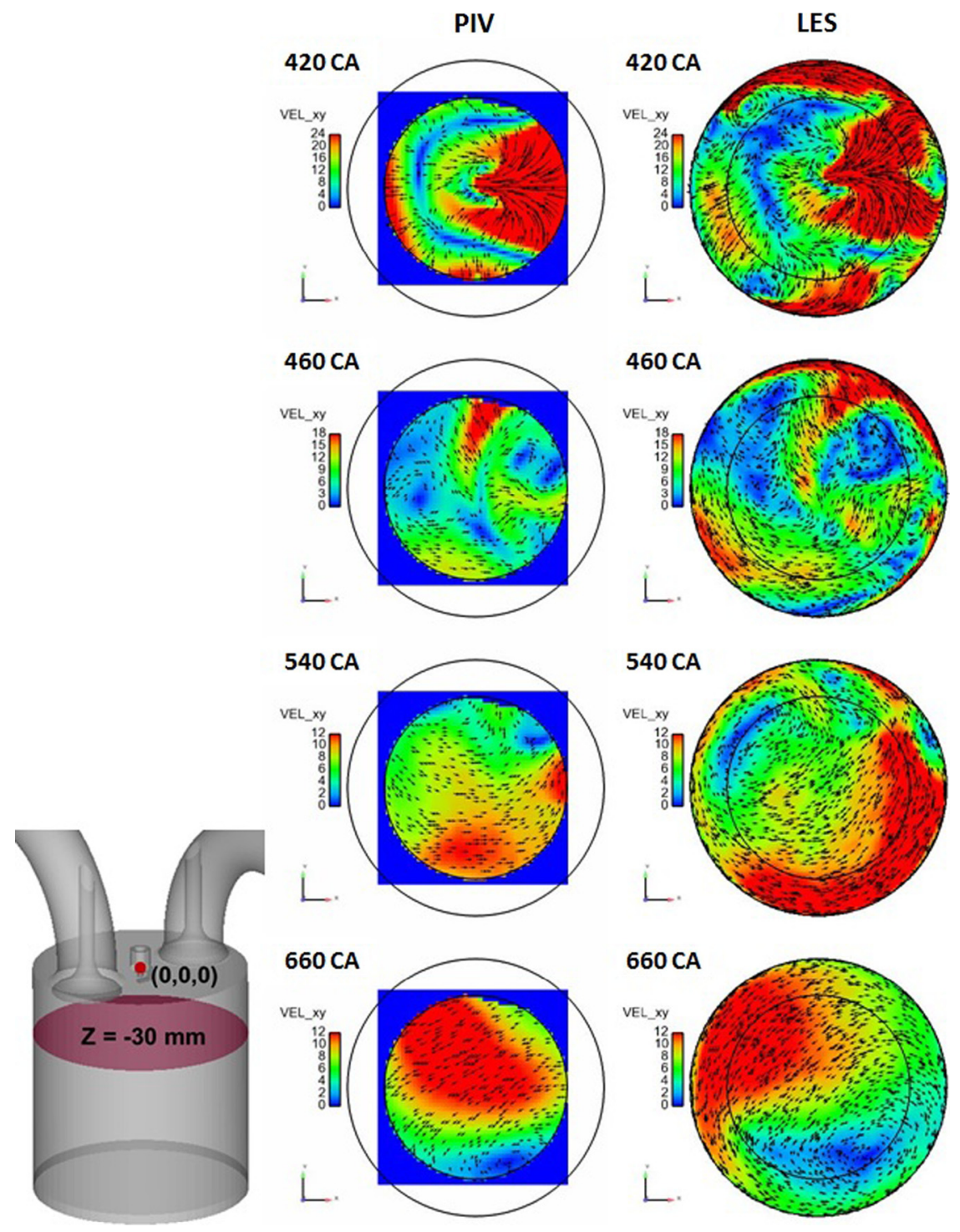

Figure 4

Comparison of velocity field over $Z=-30 \mathrm{~mm}$ plane between PIV data and LES results.

where $u_{\alpha}, v_{\alpha}$ are $x$ and $y$ components of the polar velocity in each section. NPV angle $\theta$ in Figure 6 is the angle between the NPV and the negative $X$-axis and is defined as:

$$
\theta=A T A N\left(\frac{V_{N P V}}{U_{N P V}}\right) \text {. }
$$

\section{ANALYSIS AND RESULTS}

\subsection{Pattern of In-Cylinder Swirl Ratios}

Figure 7A shows the in-cylinder swirl ratios of 18 consecutive LES cycles and the valve lift profiles in function of crank angle. Analysis of 18 consecutive LES cycles indicated two distinct CCV patterns of in-cylinder swirl ratios (SR CCV patterns). Different SR CCV patterns are evident as illustrated in Figure 7B and $\mathrm{C}$ at four selected crank angles during both the exhaust $(210,240,270$ and $300 \mathrm{CAD}$ ), intake and compression (390, 460, 540 and 660 CAD) strokes, respectively. In particular, the intake SR $\mathrm{CCV}$ patterns at different crank angles behave qualitatively similar with differences only in their magnitudes. The same cannot be said for the exhaust SR CCV patterns. The intake $\mathrm{SR} C \mathrm{CV}$ at $460 \mathrm{CAD}$ (SR CCV (460)) is chosen as a baseline to evaluate its correlations with the intake $\mathrm{SR} C \mathrm{CV}$ at different crank angles, SR CCV (CAD).

This is because of significant back flow from the exhaust port into the cylinder when the exhaust valve opens. Figure 8 shows the instantaneous Mass Flow Rates (MFR) of intake and exhaust ports for 18 LES cycles as a function of crank angle, positive for entering the cylinder and negative for leaving the cylinder. The peak exhaust MFR of 


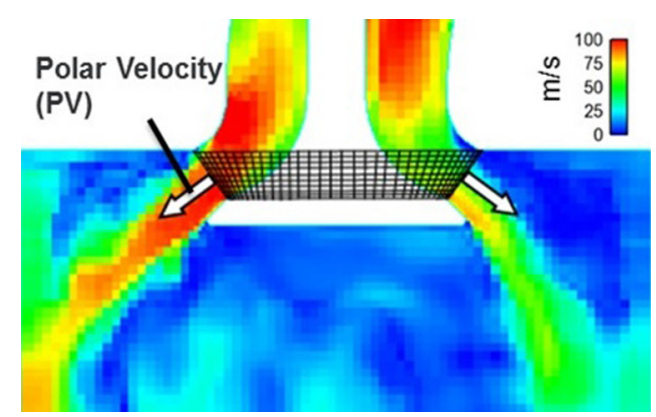

Figure 5

Schematic ring-shaped cutting surface in the valve seat region.

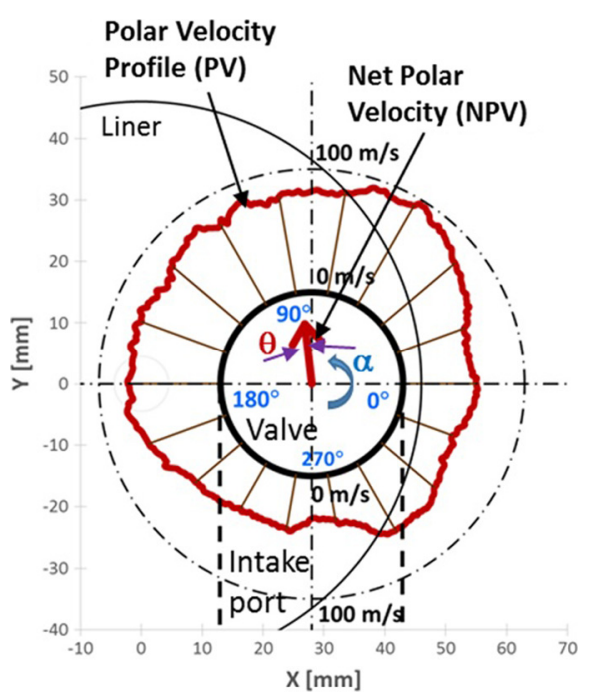

Figure 6

Intake port Polar Velocity (PV) profile and Net Polar Velocity (NPV) for LES cycle \#17 at $460 \mathrm{CAD}$.

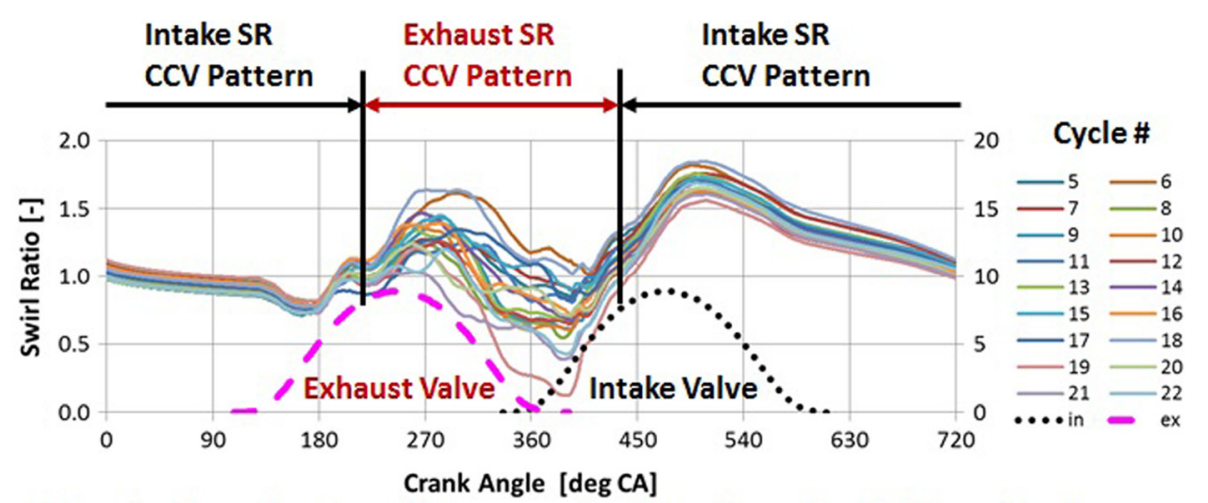

A) In-cylinder swirl ratios of 18 consecutive LES cycles and valve lift profiles in function of crank angle

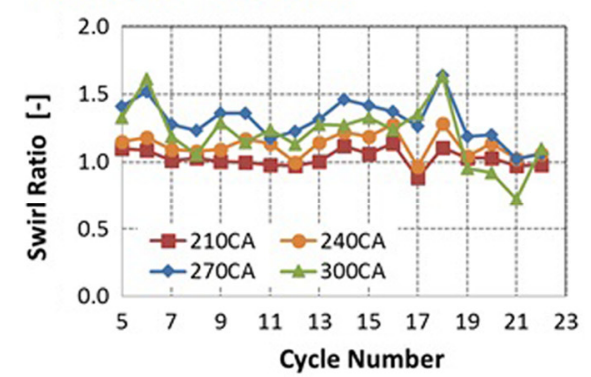

B) SR CCV patterns at 4 selected crank angles during exhaust stroke

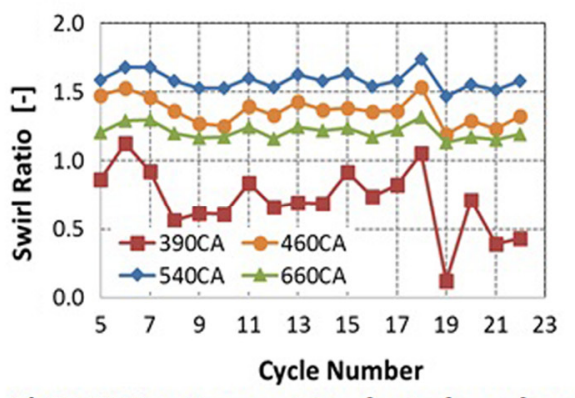

C) SR CCV patterns at 4 selected crank angles during intake and compression strokes

Figure 7

In-cylinder swirl ratios of 18 LES cycles. a) In-cylinder swirl ratios of 18 consecutive LES cycles and value lift profiles in function of crank angle. b) SR CCV patterns at 4 selected crank angles during exhaust stroke. c) SR CCV patterns at 4 selected crank angles during intake and compression strokes.

$60 \mathrm{~g} / \mathrm{s}$ is about 3 times higher than the peak intake MFR of $20 \mathrm{~g} / \mathrm{s}$. The MFR curves of the 18 LES cycles are almost identical, with a standard deviations of 0.237 and 0.047 at
180 and $450 \mathrm{CAD}$, respectively. The effect of cyclic variability of MFR on in-cylinder SR CCV patterns can be ignored. 


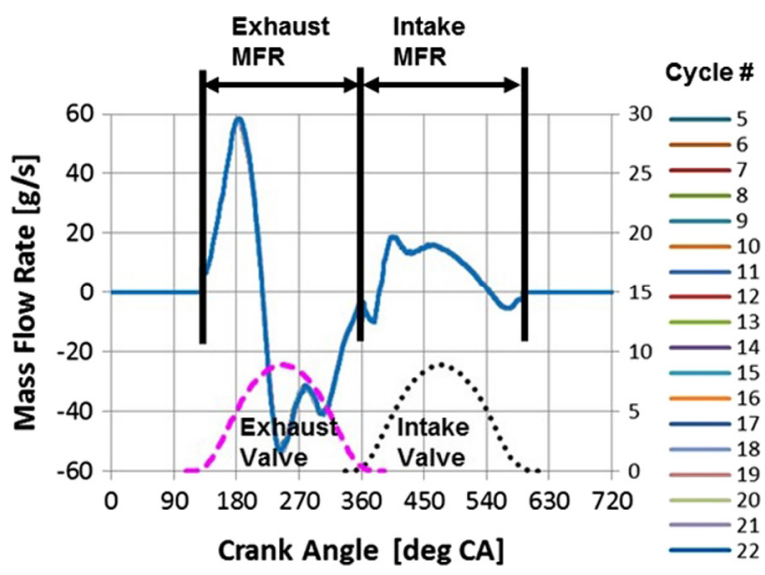

Figure 8

Mass flow rates of intake and exhaust ports for 18 LES cycles as a function of crank angle, positive for entering cylinder and negative for leaving cylinder.

The Pearson Product Moment Correlation Coefficient (PPMCC) is a measure of the linear correlation between pairs of continuous variables giving a value between +1 and -1 , where 1 is perfectly positive linear relationship, 0 is no relationship, and -1 is perfectly negative linear relationship. The correlation coefficient PPMCC (CAD) between SR $\mathrm{CCV}(460)$ and SR CCV(CAD) of 18 cycles is computed as:

see equation (4) bottom

where $\overline{S R C C V(460)}$ and $\overline{S R C C V(C A D)}$ are the average values of the SR CCV(460) and SR CCV (CAD) of 18 cycles.

PPMCC (CAD) is shown as a function of crank angle in Figure 9. During most of the time span between Intake Valve Opening (IVO) and Exhaust Valve Opening (EVO) at about $360 \mathrm{CAD}$, the PPMCC exhibits values around or higher than 0.87. This indicates that the intake port flow CCV dominates the in-cylinder flow CCV during this time. After EVO the PPMCC value drops down to 0.4 near $180 \mathrm{CAD}$, and eventually rises up to about 0.8 during the latter part of the exhaust stroke. By comparing the mass flow rates of intake and exhaust ports in Figure 8, the drastic reduction of PPMCC is caused by a back flow from the exhaust port into the cylinder, and the recovery is due to flow reversal from the cylinder to the exhaust port.

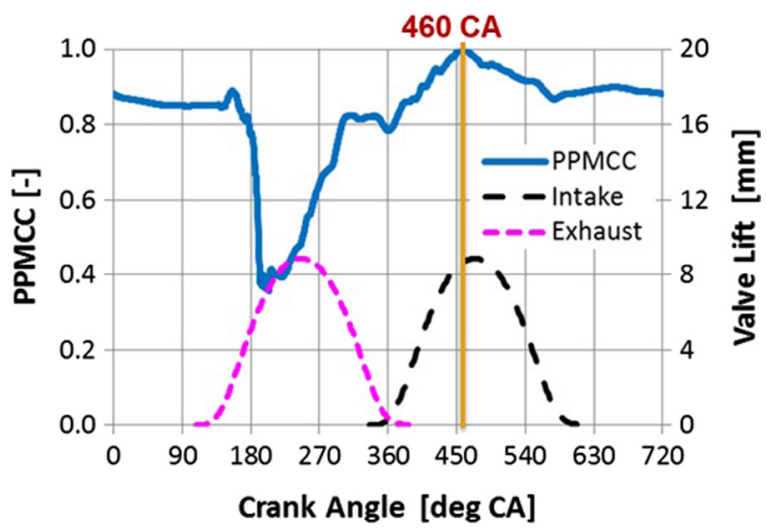

Figure 9

PPMCC (RAD) between SR CCV (CAD) and SR CCV (CAD) in function of crank angle.

In summary, it is observed that the intake flow dominates the intake SR SCCV patterns from IVO to EVO. It is also observed that the exhaust SR CCV patterns has limited impact on the intake SR CCV patterns as shown in Figure 7.

\subsection{Intake Port Polar Velocity Profile in Different Ring- Shaped Cutting Surface in Valve-Seat Region}

In order to investigate the effect of intake port flow in the valve-seat region on the intake SR CCV, six ring-shaped cutting surfaces (Stem1, Stem2, Valve3, Valve4, Valve5 and Valve6) are created at $460 \mathrm{CAD}$ as shown in Figure 10 for the intake port polar velocity analysis (Fig. 11).

Figure 11 shows the intake port $\mathrm{PV}$ profiles at $460 \mathrm{CAD}$ for the six ring-shaped cutting surfaces in the valve-seat region of cycle $\# 17$ as a function of valve circumferential angle. The NPV for each ring-shaped cutting location is also plotted as red arrows. The PV magnitude decreases gradually from upstream to downstream of the valve seat region due to increase in the flow area. The NPV magnitudes are quite small at locations Stem1 and Stem2 due to near uniform PV profile at those cutting planes. The NPV magnitudes are larger at locations Valve 3 to Valve 6 because of flow inhomogeneity caused by the offset intake valve position (Fig. 2).

$$
\begin{aligned}
& P P M C C(C A D)= \\
& \frac{\sum(S R C C V(460)-S R C C V(460))(S R C C V(C A D)-S R C C V(C A D))}{\sqrt{\sum(S R C C V(460)-S R C C V(460))^{2}} \cdot \sqrt{\sum(S R C C V(C A D)-S R C C V(C A D))^{2}}},
\end{aligned}
$$




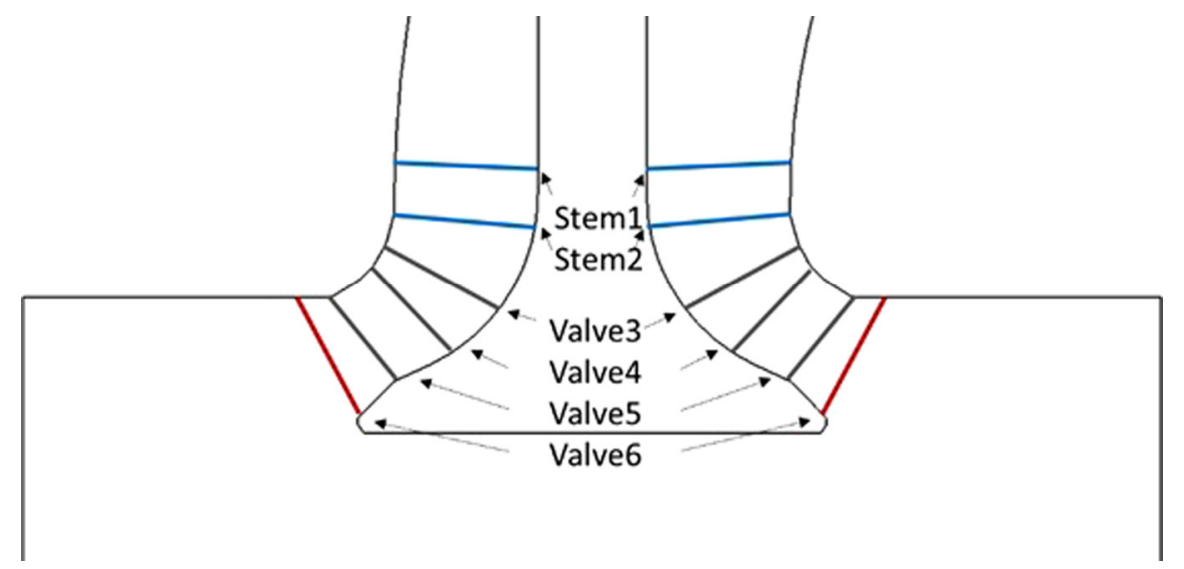

Figure 10

Ring-shaped cutting surfaces in valve-seat region at 460 CAD.
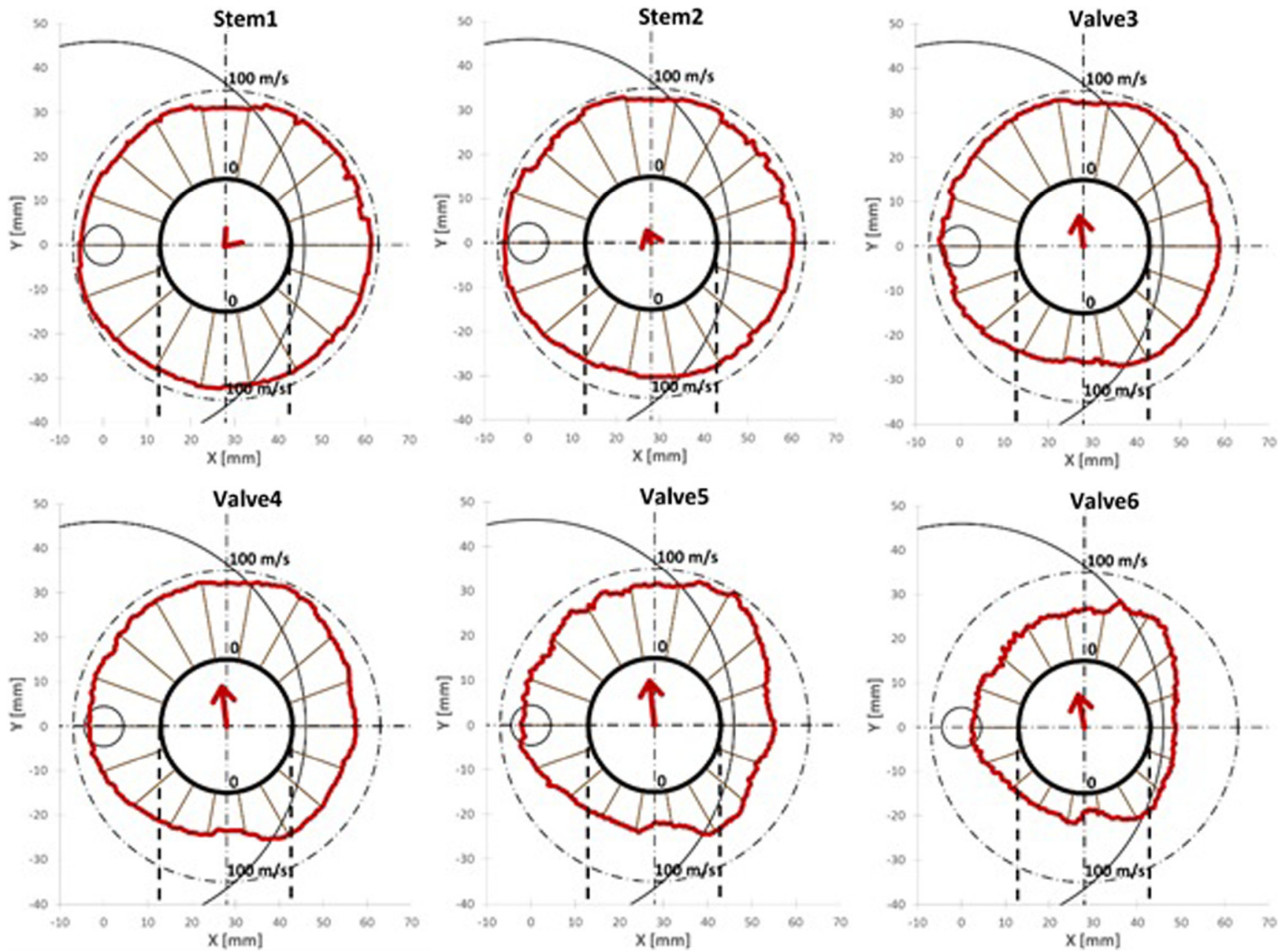

Figure 11

PV and NPV at the six ring-shaped cutting surfaces of cycle \#17 at 460 CAD. 


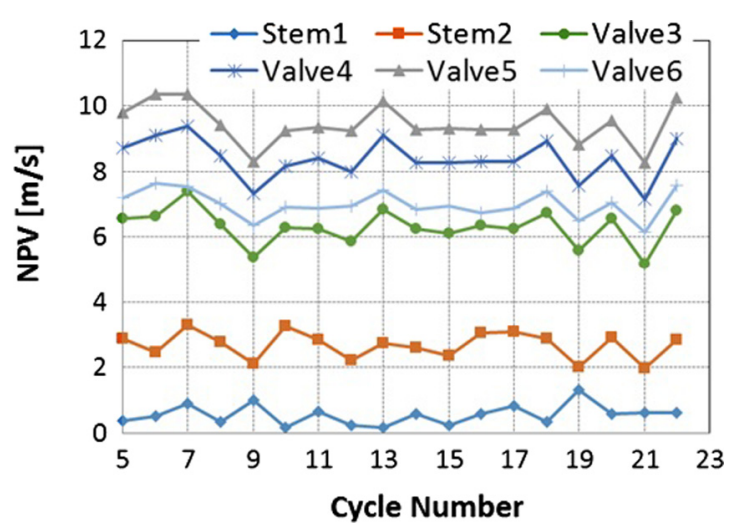

Figure 12

$\mathrm{CCV}$ of NPV magnitude at the six ring-shaped cutting surfaces at $460 \mathrm{CAD}$.

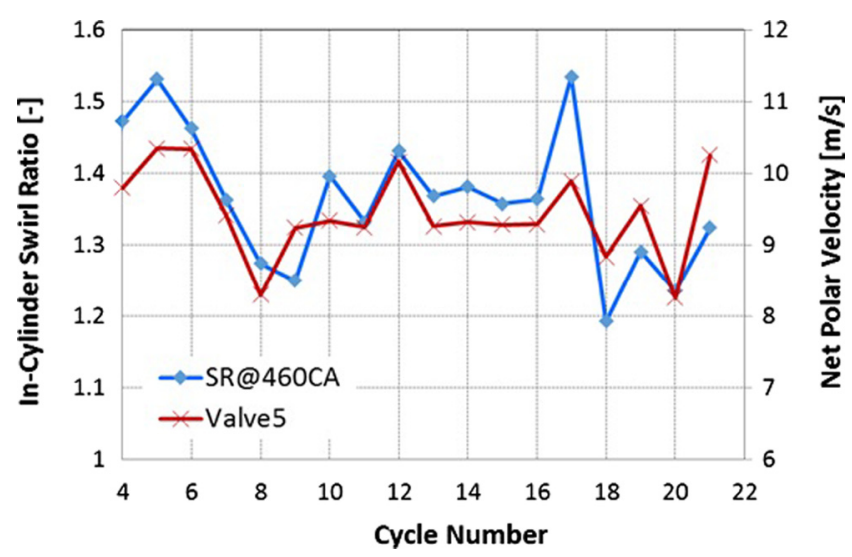

Figure 14

Comparison of $\mathrm{CCV}$ pattern between in-cylinder swirl ratio and NPV magnitude at Valve5 position at 460 CAD.

\subsection{Patterns of NPV and PV Standard Deviation}

Figure 12 shows the CCV pattern of NPV magnitude at the six ring-shaped cutting surfaces at $460 \mathrm{CAD}$ as a function of cycle number. It can be seen that the CCV patterns of NPV are very similar for all surfaces, with differences only in the magnitude, except for the Stem1 position.

Figure 13 shows the CCV pattern of PV standard deviation at the six ring-shaped cutting surfaces at $460 \mathrm{CAD}$ as a function of cycle number. It is observed that the CCV patterns of PV standard deviation are similar for all six cutting surfaces with difference only in their magnitudes. Comparing Figures 12 and 13 it is also observed that the CCV patterns of PV standard deviation and NPV magnitude are similar.

\subsection{Correlation of CCV Pattern of Swirl Ratio to NPV Magnitude and PV Standard Deviation}

Figure 14 shows comparison of CCV patterns between the in-cylinder swirl ratio and NPV magnitude at Valve5 position at $460 \mathrm{CAD}$ as a function of cycle number. The

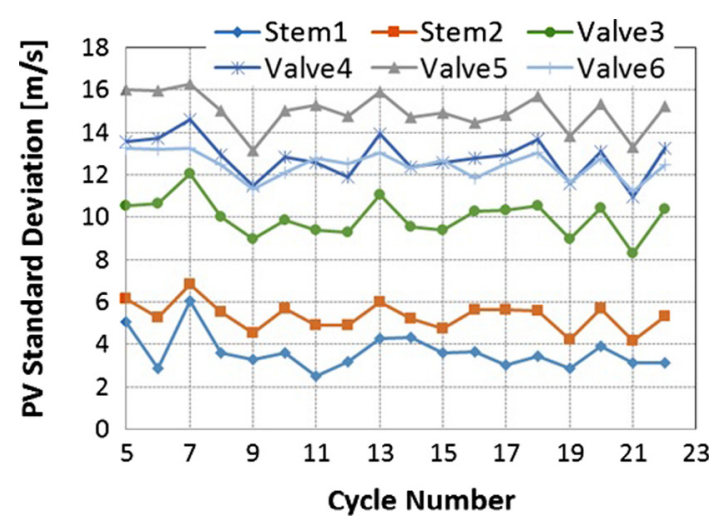

Figure 13

Cycle to cycle variation of PV standard deviation at the six ring-shaped cutting surfaces at $460 \mathrm{CAD}$.

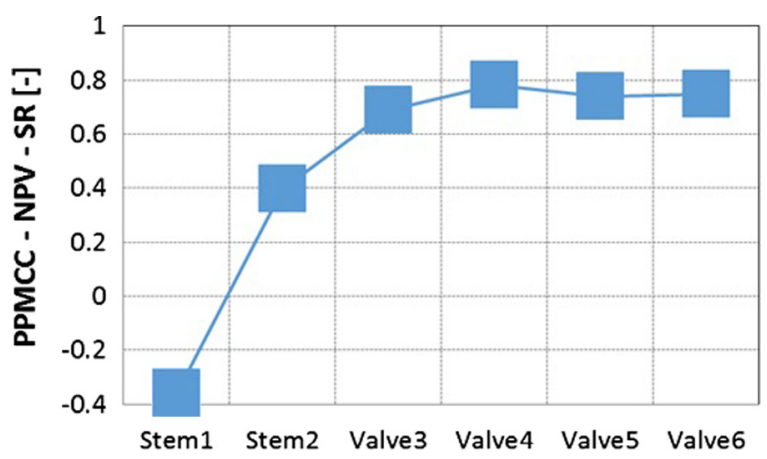

Figure 15

PPMCC between NPV magnitude at the six ring-shaped cutting surfaces and in-cylinder swirl ratio at $460 \mathrm{CAD}$.

results show that the CCV pattern of NPV magnitude correlates well with that of the CCV pattern of in-cylinder swirl ratio.

The PPMCC between NPV magnitude at the six ringshaped cutting surfaces and the in-cylinder swirl ratio at $460 \mathrm{CAD}$ is shown in Figure 15. From the surfaces Stem1 to Valve6 the PPMCC increases from -0.4 to 0.8 . The high PPMCC of 0.8 indicates that the CCV of in-cylinder SR is strongly correlated with the CCV of NPV magnitude in the valve seat region.

Figure 16 shows the PPMCC between NPV angle at the six ring-shaped cutting surfaces and the in-cylinder swirl ratio at $460 \mathrm{CAD}$. The PPMCC values vary from -0.3 to 0.2 at all surfaces which indicates that CCV of NPV angle has no correlation with $\mathrm{CCV}$ of in-cylinder swirl ratio for TCC3 engine.

Figure 17 shows the PPMCC between PV standard deviation at the six ring-shaped cutting surfaces and the incylinder swirl ratio at $460 \mathrm{CAD}$. The $\mathrm{CCV}$ of PV standard deviation shows similar behavior than the CCV of NPV 


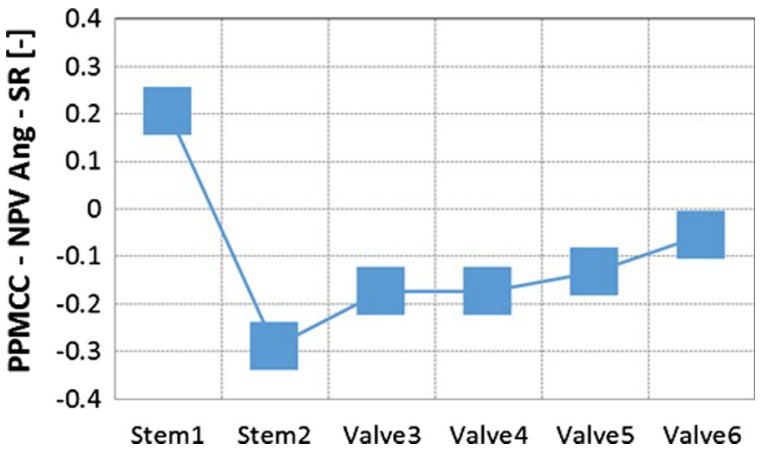

Figure 16

PPMCC between NPV angle at the six ring-shaped cutting surfaces and in-cylinder swirl ratio at $460 \mathrm{CAD}$.

magnitude presented in Figure 15. It further indicated that correlation of CCV patterns between the port flow in the valve seat region and the in-cylinder swirl ratio is built up gradually from section Stem1 to Valve6, i.e. from upstream to downstream in the valve-seat region for the intake port examined. In other words, CCV of flow in the valve seat region for the TCC3 engine dominates the $\mathrm{CCV}$ of incylinder swirl ratio.

\section{CONCLUSION}

An analysis of TCC3 engine LES results was carried out to investigate $\mathrm{CCV}$ correlation between in-cylinder swirl ratio and flow in the valve seat region of the intake port. A polar velocity profile at selected ring-shaped cutting surfaces in the valve seat region was calculated as an indicator of port flow uniformity. A net polar velocity was defined by performing the vector sum of the polar velocity on the ringshaped cutting surface. A standard deviation of PV was also calculated from azimuthal distribution of PV magnitudes relative to its mean value. The following observations were reached:

- Strong correlation exists between CCV patterns of incylinder swirl ratio at different crank angle positions from IVO to EVO, which suggests the in-cylinder flow CCV is dominated by the intake flow;

- CCV of in-cylinder swirl ratio at all crank angle positions from IVO to EVO also exhibits strong correlation with the net polar velocity magnitude and polar velocity standard deviation. The correlation improves when the ring-shaped cutting surface is moved from upstream to downstream in the valve seat region.

This study reveals that there is strong correlation between $\mathrm{CCV}$ of flow in the valve seat region and the CCV of incylinder swirl ratio.

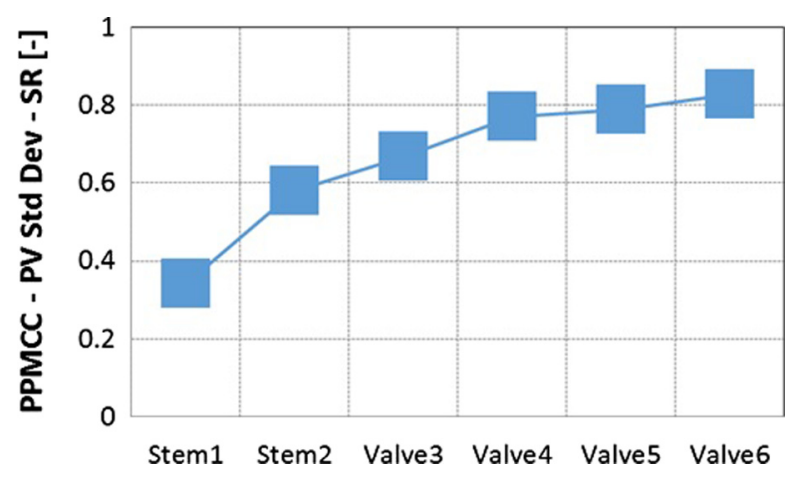

Figure 17

PPMCC between PV standard deviation at the six ring-shaped cutting surfaces and in-cylinder swirl ratio at $460 \mathrm{CAD}$.

\section{ACKNOWLEDGMENT}

The authors are thankful to Prof Volker Sick of the University of Michigan and Dr. Christian Angelberger of IFPEN for their technical discussions and contributions.

\section{REFERENCES}

1 Rutland C.J. (2011) Large-Eddy Simulations for internal combustion engines - A review, Int. J. Engine Res. 12, 421-451.

2 Schiffmann P., Gupta S., Reuss D., Sick V., Yang X., Kuo T.-W. (2016) TCC3-Engine benchmark for large eddy simulation of IC engine flows, Oil Gas Sci. Technol. - Rev. IFP Energies nouvelles 71, 3, 1-27.

3 Kuo T.-W., Yang X., Gopalakrishnan V., Chen Z. (2014) LargeEddy Simulation (LES) for IC engine flows, Oil Gas Sci. Technol. - Rev. IFP Energies nouvelles 69, 61-81.

4 Liu K., Haworth D.C., Yang X., Gopalakrishnan V. (2013) Large-Eddy Simulation of motored flow in a two-valve piston engine: Pod analysis and cycle-to-cycle variations, Flow Turbul. Combust. 91, 373-403.

5 Abraham P., Yang X., Gupta S., Kuo T.-W., Reuss D., Sick V. (2015) Flow-pattern switching in a motored spark ignition engine, Int. J. Engine Res. 16, 323-339.

6 Buhl S., Hartmann F., Hasse C. (2015) A dynamic oneequation non-viscosity LES model, Oil Gas Sci. Technol. Rev. IFP Energies nouvelles, DOI:10.2516/ogst/2015021.

7 Zentgraf F., Baum E., Böhm B., Dreizler A., Peterson B. (2016) On the turbulent flow in piston engines: Coupling of statistical theory quantities and instantaneous turbulence, Phys. Fluids 28, 045108.

8 Yang X., Gupta S., Kuo T.-W., Gopalakrishnan V. (2014) Rans and les of IC engine flows - A comparative study, J. Eng. Gas Turbines Power 136, 5, 051507-1-051507-9.

9 Yang X., Keum S., Kuo T.-W. (2016) Effect of valve opening/ closing setup on CFD prediction of engine flows, J. Eng. Gas Turbines Power 138, 081503-1-081503-16.

10 Richards K.J., Senecal P.K., Pomraning E. (2013) CONVERGE 2.1.0 Theory Manual, A three-dimensional computational fluid dynamics program for transient or steady state flow with complex geometries, Converg. Sci. Inc., pp. 1-442 
11 Senecal P.K., Richards K.J., Pomraning E., Yang T., Dai M.Z., Dai McDavid R.M., Patterson M.A., Hou S., Shethaji T. (2007) A new parallel cut-cell cartesian CFD code for rapid grid generation applied to in-cylinder diesel engine simulations, SAE Technical Paper 2007-01-0159.

12 Rhie C.M., Chow W.L. (1983) Numerical study of the turbulent flow past an airfoil with trailing edge separation, AIAA J. 21, 1525-1532.

13 Issa R.I. (1986) Solution of the implicitly discretised fluid flow equations by operator-splitting, J. Comput. Phys. 62, 1, 40-65.

14 Pomraning E., Rutland C.J. (2002) A dynamic one-equation non-viscosity LES model, AIAA J. 40, 689-701.
15 Werner H., Wengle H. (1991) Large-Eddy Simulation of turbulent flow over and around a cube in a plane channel, in: Proceedings of the Eighth Symposium on Turbulent Shear Flows, Vol. 2, pp. 1941-1946.

Manuscript submitted in 14 November 2016 Manuscript accepted in 16 October 2017 Published online in December 2017 